\title{
Characterization of Botrytis cinerea Isolates From Grape Vineyards in China
}

Yanjie Zhang, Agricultural University of Hebei, National Engineering Research Center for Agriculture in Northern Mountainous Areas, Biological Control Center of Plant Diseases and Plant Pests of Hebei Province, Baoding, China 071001; Xinghong Li, Institute of Plant and Environment Protection, Beijing Academy of Agriculture and Forestry Sciences, Beijing, China 100089; Fengying Shen, Agricultural University of Hebei, Baoding, China 071001, and North University of Hebei, Zhangjiakou, China 075000; and Huanping Xu, Yaning Li, ${ }^{\dagger}$ and Daqun Liu, ${ }^{\dagger}$ Agricultural University of Hebei, National Engineering Research Center for Agriculture in Northern Mountainous Areas, Biological Control Center of Plant Diseases and Plant Pests of Hebei Province, Baoding, China 071001

\begin{abstract}
One hundred thirty-five single-spore isolates were collected from grape vineyards from 15 provinces or autonomous regions belonging to five viticulture climatic zones in China. All the isolates were identified as Botrytis cinerea based on their morphological and molecular characters. The 135 isolates were all heterothallic isolates. Seventy-one isolates belonged to the MAT1-1 type and 64 were characterized to MAT1-2 type. All the isolates studied belonged to Group II based on PCR-RFLP of the $B c-h c h$ locus. The four TE genotypes, transposa, Boty-only, Flipper-only, and vacuma, comprised $51.9 \%, 33.3 \%, 10.4 \%$, and $4.5 \%$, respectively, of the total population. The frequency of transposa was highest in the total population and the most of any subpopulation (each viticulture climatic zone), and Boty-only was highest in warm areas (46.2\%). Vacuma was mainly

distributed in northern China, although in small amounts, and Flipper-only was mainly was distributed in humid tropical areas (42.9\%). A microsatellite analysis of $B$. cinerea populations was performed to assess the genetic population structure. A total of 127 different MLGs were identified among 135 B. cinerea isolates, with a genotypic diversity of 0.9991 . The transposa population isolates showed higher genetic diversity than other populations. Pairwise tests of genetic differentiation among four TE-type populations yielded generally low to high Gst values. All isolates belonged to two genetic clusters. The population microsatellite diversity and genetic structure had a certain correlation with the TE type and geographic origin. This is the first report of the genotypic diversity of $B$. cinerea isolates from grape vineyards across China.
\end{abstract}

Grapes, which include table and wine grapes, are an important commercial crop grown throughout the world, with a total annual planted area of 7.5 million ha and a total annual production of 75.7 million tons in 2015. In China, the planted grapevine area and yield in 2015 was 0.83 million ha and 12.6 million tons, respectively (http:// www.oiv.int). According to the OIV's statistics, China ranks as the second largest country in the world in terms of vineyard surface area.

Botrytis cinerea Pers. is one of the most important necrotrophic pathogens and is most destructive to the mature or senescent tissues of its dicotyledonous hosts. Botrytis cinerea decreases grape production during both pre- and postharvest stages. In addition to grapes, B. cinerea can infect more than 200 plant species, including Cruciferae, Cucurbitaceae, Solanaceae, and Rosaceae. It can infect the host plant from the seedling stage to the maturation stage and cause spoilage during storage and transport. The percentage of grape clusters affected by the disease in seriously affected vineyards can be as high as $40 \%$ before harvest, causing $20 \%$ yield losses (Zhang et al. 2013). The disease has been reported to cause important losses in Chardonnay, Selah, and Italian Riesling vineyards in western China (Zhang et al. 2013). Expenses related to controlling this disease can reach up to AUS \$52 million/year in Australia, US \$22.4 million/year in Chile and SA Rand 25 million rand/year in South Africa (Dean et al. 2012). Globally, the cost of controlling the disease can reach $€ 1$ billion/year (Dean et al. 2012).

Historically the identification of Botrytis spp. was based on colony morphology and measurements of conidia and conidiophores. Rigotti

${ }^{\dagger}$ Corresponding authors: Yaning Li; E-mail: yaning22@163.com and Daqun Liu; E-mail: ldq@hebau.edu.cn

*The $\boldsymbol{e}$-Xtra logo stands for "electronic extra" and indicates that four supplementary tables and one supplementary figure is published online.

Accepted for publication 29 August 2017.

() 2018 The American Phytopathological Society et al. (2002) used random amplified polymorphic DNA (RAPD) to develop a specific primer pair C $729+/-$ for specific identification of $B$. cinerea by PCR. There are two mating-type genes found in ascomycetes: MAT1-1 and MAT1-2. Mating-type locus is the key regulatory factor controlling crossing. The MAT1-1 sequence contains three genes that encode $\alpha$-box protein MAT1-1-1, HPG domain MAT1-1-2, and HMG domain MAT1-1-3, and the MAT1-2 sequence generally only contains HMG DNA-binding domain (Debuchy and Turgeon 2006). Research indicates that the sexual recombination of $B$. cinerea involving MAT1-1 and MAT1-2 is widespread in nature (Faretra et al. 1988). Faretra et al. (1988) found that approximately 6\% of ascospore progeny and $16 \%$ of field isolates were homothallic (both MAT1-1 and MAT1-2), with the rest of the isolates being heterothallic (either MAT1-1 or MAT1-2).

Botrytis cinerea is a phytopathogenic fungus with significant genetic diversity. The RFLP (Giraud et al. 1997; Muñoz et al. 2010), RAPD (Esterio et al. 2011; Muñoz et al. 2002; Thompson and Latorre 1999), microsatellite (Fournier et al. 2002; Kecskeméti et al. 2014), and AFLP (Moyano et al. 2003) techniques have all been used to studied its variation. Fournier et al. (2003) developed PCRRFLP for the $B c$-hch locus to divide $B$. cinerea into two genetic groups, Groups I and II, based on multiple-gene genealogies approach. Groups I and II are currently described as phylogenetic species, as well as cryptic species, and differ in their phenology, host range, size of asexual spores, and vegetative compatibility (Fournier et al. 2005). Walker et al. (2011) carried out extensive research on Group I and named it B. pseudocinerea while Group II was named $B$. cinerea sensu stricto. Fournier et al. (2002) characterized nine polymorphic microsatellite loci in the fungus $B$. cinerea, and many researchers (Huang 2012; Isenegger et al. 2008; Kecskeméti et al. 2014; Wessels 2012; Zhang 2015) studied genetic diversity of $B$. cinerea by these polymorphic microsatellite loci.

Two transposable elements (TEs), Flipper and Boty, were found in B. cinerea. Diolez et al. (1995) identified a retroelement from B. cinerea related to the gypsy class of long terminal repeat (LTR)containing transposon and named it Boty. Based on the presence or 
absence of the transposon, these authors proposed that Boty-containing and Boty-deficient groups represent two lineages in the population of B. cinerea. Then Levis et al. (1997) found another TE, Flipper, a mobile Fot1-like transposon carrying an insertion sequence within the coding region of the nitrate reductase gene. Giraud et al. (1997) defined two sibling sympatric species based on the presence or absence of Boty and Flipper: transposa and vacuma. Transposa isolates possess both Boty and Flipper, whereas these elements are absent in vacuma isolates. Even if both transposa and vacuma occur in the same plant, their relative frequencies are significantly different (Giraud et al. 1999). In later research, the strains that only possessed either Boty or Flipper were discovered, and further searches for these TEs followed.

Despite the economic impact of gray mold on grapes, there is no detailed study of $B$. cinerea populations on grape in China. Thus, the main objective of this work was to analyze the characterization and genetic structure of $B$. cinerea populations from grapes from five viticulture climatic zones in China. Transposons, phylogenetic groups, mating types, and microsatellite genetic diversity of isolates from grapes were detected and analyzed. We hope this study will be an important supplement to data on the status of $B$. cinerea in Chinese grape vineyards, and will provide a basis for controlling grape gray mold.

\section{Materials and Methods}

Isolations, cultivation, initial identification, and mycelial collection of $\boldsymbol{B}$. cinerea. Based on the climate conditions for grape growth, He (1999) divided Chinese grape planting areas into six viticulture climatic zones: cold-cool-climate area; cool-temperature area; medium-temperature area; warm area; torrid-climate area; and humid-tropical region. In this study, all isolates were collected from naturally infected grapes from 53 vineyards in five viticulture climatic zones in China from 2010 to 2016 (Supplementary Table $\mathrm{S} 1)$. After incubation of plant material and diseased grapes in the dark at $21^{\circ} \mathrm{C}$ and $80 \%$ relative humidity condition, isolates were obtained and purified by monospore isolation. To initially identify the isolates,

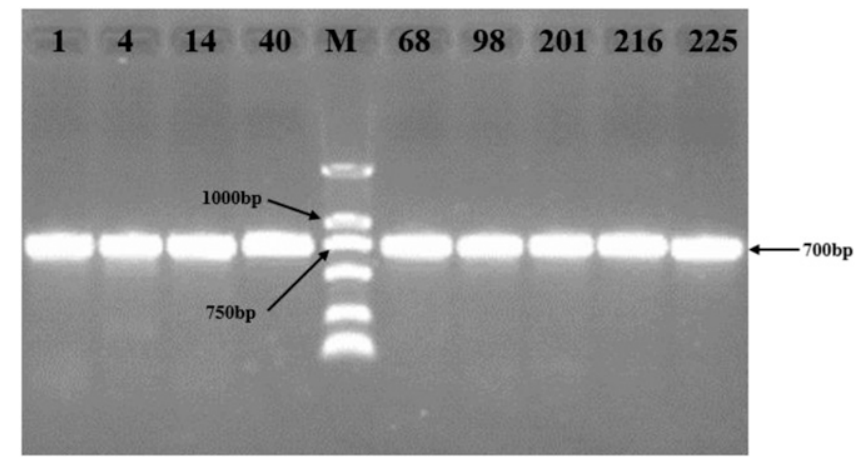

Fig. 1. Gel electrophoretic profile of PCR amplification using specific primer pairs for C729+/- that amplified a 700-bp fragment. Numerals on the top of the gel represent the isolate number. M is DNA Marker 2000, Bioteke Corporation, Beijing.

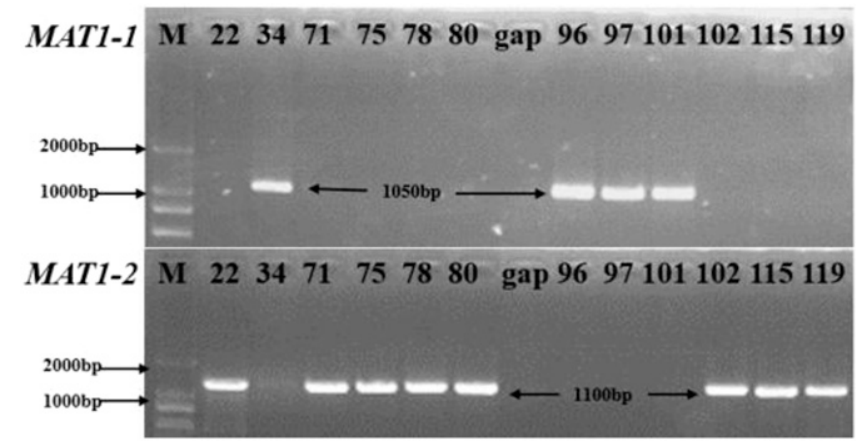

Fig. 2. Gel electrophoretic profile of the mating-type PCR amplification. Numerals on the top of the gel represent the isolate number. M is DNA Marker 2000, Bioteke Corporation, Beijing. colony characteristics including mycelia and conidiophores were observed under the microscope according to Lu (2001) and Mirzaei et al. (2008). A total of 135 isolates (Supplementary Table S1) were obtained and stored at $4^{\circ} \mathrm{C}$ on potato dextrose agar (PDA). Singlespore isolates were cultivated on potato dextrose agar (PDA) at $21^{\circ} \mathrm{C}$ for 7 days, and the mycelia and conidia were scraped into 2-ml centrifugation tubes and stored at $-20^{\circ} \mathrm{C}$.

DNA extraction. Genomic DNA from the aerial mycelia and conidia collected from $B$. cinerea was extracted using the SDS-CTAB method described by Zhang (2010b), with slight modifications $\left(10 \mathrm{mg} / \mathrm{ml} \mathrm{RNase}\right.$ treated time was $2 \mathrm{~h}$ instead of 2 days, at $\left.37^{\circ} \mathrm{C}\right)$. The quality of the DNA was assessed on $1 \%(\mathrm{w} / \mathrm{v})$ agarose gels, and the gels were observed in a gel imaging system (UVItec, Cambridge, England). The concentration of genomic DNA was measured on a BioPhotometer Plus (Eppendorf, Hamburg, Germany). DNA extraction was repeated in at least triplicate for each isolate, and used for the subsequent PCR analyses.

Nuclear gene sequencing and phylogenetic analysis. Thirty-six of the represented isolates of four TE types were chosen to identify the Botrytis isolates to species level. Primer pairs G3PDHfor/G3PDHrev, HSP60for/HSP60rev, and RPB2for/RPB2rev (Supplementary Table S3) were used to amplify partial fragments of the glyceraldehyde-3phosate dehydrogenase (G3PDH), heat-shock protein 60 (HSP60), and DNA-dependent RNA polymerase subunit II (RPB2), respectively (Staats et al. 2005). PCR (Supplementary Table S4) was carried out in a 2720 thermal cycler (Applied Biosystems, Carlsbad, CA). PCR products were treated with Takara miniBEST agarose gel DNA extraction kit (Takara Biomedical Technology Co., Ltd., China, Beijing) according to manufacturer's protocols. Purified PCR products were directly sequenced by Sangon Biotech (Shanghai, China). G3PDH, HSP60, and $R P B 2$ partial gene sequences of 36 representative isolates in this study and 57 representatives (Supplementary Table S2) of the genus Botrytis were included in the phylogenetic analysis with Monilinia fructigena strain 9201 and Sclerotinia sclerotiorum stain 484 as

Table 1. Distribution and mating-type frequencies of $B$. cinerea isolates

\begin{tabular}{|c|c|c|c|c|c|}
\hline $\begin{array}{l}\text { Viticulture } \\
\text { climate zone }\end{array}$ & Location & MAT1-1 & MAT1-2 & $\chi^{2 \mathrm{a}}$ & Total \\
\hline \multirow{6}{*}{$\begin{array}{l}\text { Cool- } \\
\text { temperature } \\
\text { area }\end{array}$} & Lanzhou, Gansu & 9 & 6 & $\ldots$ & 15 \\
\hline & Zhangye, Gansu & 8 & 5 & $\ldots$ & 13 \\
\hline & Xingcheng, Liaoning & 2 & 6 & $\ldots$ & 8 \\
\hline & Yongning, Ningxia & 1 & 0 & $\ldots$ & 1 \\
\hline & Qingxu, Shanxi & 2 & 1 & $\ldots$ & 3 \\
\hline & Total & 22 & 18 & 0.23 & $\ldots$ \\
\hline \multirow{7}{*}{$\begin{array}{l}\text { Medium- } \\
\text { temperature } \\
\text { area }\end{array}$} & Changli, Hebei & 1 & 1 & $\ldots$ & 2 \\
\hline & Jining, Shandong & 0 & 5 & $\ldots$ & 5 \\
\hline & Longkou, Shandong & 6 & 4 & $\ldots$ & 10 \\
\hline & Laizhou, Shandong & 2 & 0 & $\ldots$ & 2 \\
\hline & Penglai, Shandong & 12 & 8 & $\ldots$ & 20 \\
\hline & Zhaoyuan, Shandong & 0 & 5 & $\ldots$ & 5 \\
\hline & Total & 21 & 23 & 0.02 & $\ldots$ \\
\hline \multirow[t]{6}{*}{ Warm area } & Changping, Beijing & 1 & 4 & $\ldots$ & 5 \\
\hline & Shunyi, Beijing & 1 & 0 & $\ldots$ & 1 \\
\hline & Yanqing, Beijing & 10 & 6 & $\ldots$ & 16 \\
\hline & Xingtai, Hebei & 1 & 0 & $\ldots$ & 1 \\
\hline & Chadian, Tianjin & 1 & 2 & $\ldots$ & 3 \\
\hline & Total & 14 & 12 & 0.04 & $\ldots$ \\
\hline \multirow{2}{*}{$\begin{array}{l}\text { Torrid- } \\
\text { climate area }\end{array}$} & Shangshui, Henan & 0 & 2 & $\ldots$ & 2 \\
\hline & Total & 0 & 2 & 0.50 & $\ldots$ \\
\hline \multirow{8}{*}{$\begin{array}{l}\text { Humid- } \\
\text { tropical } \\
\text { region }\end{array}$} & Guilin, Guangxi & 3 & 0 & $\ldots$ & 3 \\
\hline & Zhouji, Hubei & 3 & 1 & $\ldots$ & 4 \\
\hline & Huaihua, Hunan & 4 & 0 & $\ldots$ & 4 \\
\hline & Changzhou, Jiangsu & 0 & 1 & $\ldots$ & 1 \\
\hline & Fengxian, Shanghai & 2 & 4 & $\ldots$ & 6 \\
\hline & Jiading, Shanghai & 0 & 2 & $\ldots$ & 2 \\
\hline & Hangzhou, Zhejiang & 2 & 1 & $\ldots$ & 3 \\
\hline & Total & 14 & 9 & 0.70 & $\ldots$ \\
\hline Total & $\ldots$ & 71 & 64 & 0.27 & 135 \\
\hline
\end{tabular}

${ }^{\mathrm{a}} \chi^{2}$ value based on a 1:1 ratio and 1 d.f. 
outgroup (Staats et al. 2005; Walker et al. 2011; Zhang 2010a, 2015). A phylogenetic tree was constructed combining G3PDH, HSP6O, and $R P B 2$ sequence data using MEGA 6.0 with the maximum likelihood analyses. Multiple sequence alignments were performed with Clustal W with the default parameters, and alignments of DNA sequences were examined by the maximum-likelihood (ML) method in MEGA 6.0 (Tamura et al. 2013). Support for each branch in the inferred trees was evaluated by 1000 bootstrap replications.

Confirmation of $B$. cinerea isolates by molecular methods. Molecular identification was carried out using a $B$. cinerea-specific primer pair C729+/- (Supplementary Table S3) developed by Rigotti et al. (2002). The PCR reaction (Supplementary Table S4) was carried out in a 2720 thermal cycler (Applied Biosystems). The reactions were repeated three times for each PCR. Amplification of the approximately 700-bp fragment demonstrated that the isolate was $B$. cinerea.

Determination of the mating type. Mating types MAT1-1 and MAT1-2 were determined using primers developed by van Kan et al. (2010) (Supplementary Table S3). The PCR reaction (Supplementary Table S4) was performed in a T100 Thermal Cycler (BioRad, Hercules, CA).

MAT1-1 (only MAT1-1 gene) and MAT1-2 (only MAT1-2 gene) isolates were heterothallic, and MAT1-1/1-2 isolates were homothallic, containing both the MAT1-1 and MAT1-2 genes. A $\chi^{2}$ test was performed to determine the goodness of fit of this distribution compared with the expected mating-type ratio of 1:1 by the following formula (Gai 2000):

$$
\chi^{2}=\cdot(|A-a|-1)^{2} / n
$$

where $A=$ the number of MAT1-1 type isolates, $a=$ the number of MAT1-2 type isolates, $n=A+a$, $\mathrm{df}=1$, and the level of significance was $\alpha=0.05 . \chi_{0.05,1}^{2}=3.84$, if $\chi^{2}<\chi^{2}{ }_{0.05,1}$, then $P>0.05$, and the mating-type distribution fits $1: 1$.

Characterization of the $\boldsymbol{B c}$-h $\boldsymbol{c h}$ locus. The genetic group was determined using the specific primer pair 262 and $520 \mathrm{~L}$ (Fournier et al. 2003) (Supplementary Table S3) to amplify a partial Bc- $h c h$ locus, followed by digestion by Hha I. PCR amplifications (Supplementary Table S4) were performed in a Veriti 96-Well Thermal Cycler (Applied Biosystems). After PCR, the amplicons were digested by Hha I (Thermo Fisher Scientific Inc., Waltham, MA) at $37^{\circ} \mathrm{C}$ for $10 \mathrm{~h}$, and each 30- $\mu$ l digestion system contained $10 \mu \mathrm{l}$ of amplicon, $2 \mu \mathrm{l}$ of Tango buffer, $0.5 \mu \mathrm{l}$ of Hha I, and $17.5 \mu \mathrm{l}$ of nuclease-free water. The digested products were separated on $2.0 \%$ agarose gels containing Goodview nucleic acid stain. After electrophoresis, gels were photographed by a gel imaging system. The presence of restriction fragments at $601 \mathrm{bp}$ and $517 \mathrm{bp}$ characterized each isolate into Groups I and II, respectively (Fournier et al. 2003). The PCR reaction and digestion were repeated three times.

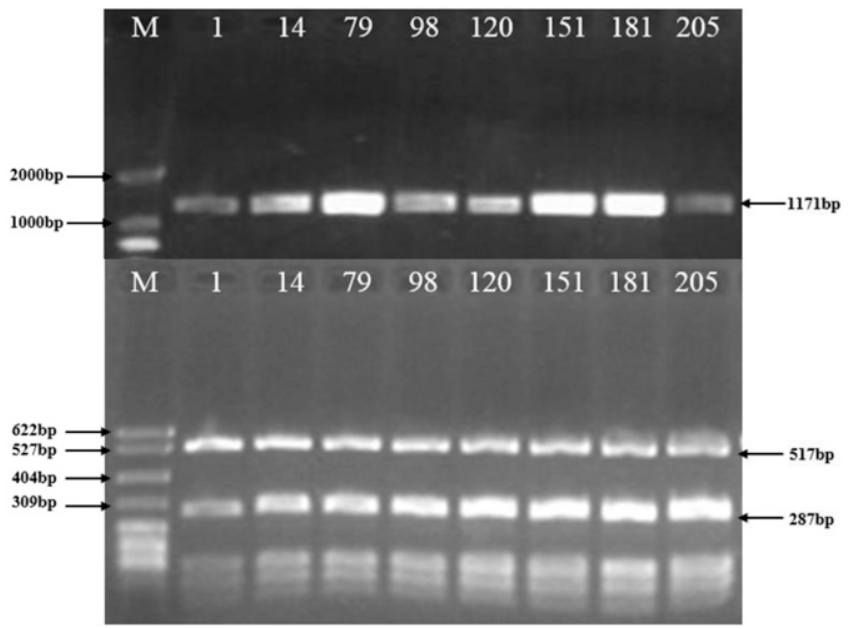

Fig. 3. Gel electrophoretic profile of the Bc-hch locus and the product digested by Hha I. Numerals on the top of the gel represent the isolate number. $M$ above is DNA Marker 2000, Bioteke Corporation, Beijing; M below is pBR322 DNA/Msp I, Tiangen Biotech Co., Ltd., Beijing.
Detection of transposons Flipper and Boty in B. cinerea. Flipper and Boty were amplified using the PCR primer pairs F300/ F1550 (Levis et al. 1997) and Boty-F/R (Muñoz et al. 2010) (Supplementary Table S3), respectively. The PCR reaction (Supplementary Table S4) was carried out in a Veriti 96-Well Thermal Cycler (Applied Biosystems). The reactions were repeated three times for each PCR.

The isolates were divided into four molecular types based on the presence or absence of the transposons Flipper and Boty. The isolates containing both Flipper and Boty were of the transposa type, and the isolates lacking transposons were of the vacuma type. In addition, isolates that contained only Boty or only Flipper were named Botyonly and Flipper-only, respectively.

Microsatellite amplification and analysis. Amplification reactions (Supplementary Table S4) for the nine microsatellite loci described by Fournier et al. (2002) were carried out using a 2720 thermal cycler (Applied Biosystems). Based on the sizes of the 9 microsatellite markers, a haplotypic profile could be assigned to each isolate, defining multilocus genotypes (MLG). Genotyping was repeated for some (but not all) of the isolates to confirm the results.

Population genetic analysis. The analysis was carried out for $B$. cinerea isolates of four TE-type populations and different viticulture climatic regions, and complete 9-microsatellite haplotypic profiles were obtained. Computation of the Nei's gene diversity $(H)$, Shannon's information index $(I)$, genetic differentiation coefficient (Gst), gene flow $(N m, N m=0.5(1-G s t) / G s t)$, Nei's unbiased genetic identity, and genetic distance were performed with POPGENE 32 version 1.31 (Yeh et al. 1999). ARLEQUIN 3 (Excoffier et al. 2005) was used for a hierarchical analysis of molecular variance (AMOVA) among B. cinerea populations.

The number of different multilocus genotypes (MLG) was computed with MULTILOCUS 1.3b (Agapow and Burt 2001). To test for genetic recombination, the standardized index of association $\left(\mathrm{r}_{\mathrm{D}}\right)$ was calculated using MULTILOCUS 1.3b (Agapow and Burt 2001). The $r_{D}$ index is a measure of the multilocus linkage disequilibrium, which gives information on whether two different individuals sharing the same allele at one locus are more likely to share an allele at another locus. For each pair of isolates, the number of loci with respect to which they differ is calculated, and the variance of this number is compared with that expected if there is no linkage disequilibrium. The $r_{D}$ index is equal to zero if there is no linkage disequilibrium, and it increases as linkage disequilibrium increases.

Bayesian inference cluster analysis of $B$. cinerea isolates of four TE-type populations was implemented using the STRUCTURE v. 2.3.4 program (Pritchard et al. 2000). This method assigns individual isolates to an initially unknown number of $\mathrm{K}$ genetic populations if their genotypes indicate that they are admixed, ignoring any prior data on sampling locations. To estimate the most probable number of genetic populations (K), 10 independent runs for each $\mathrm{K}$ from 1 to 15 were carried out with 100000 burn-in steps followed by 100

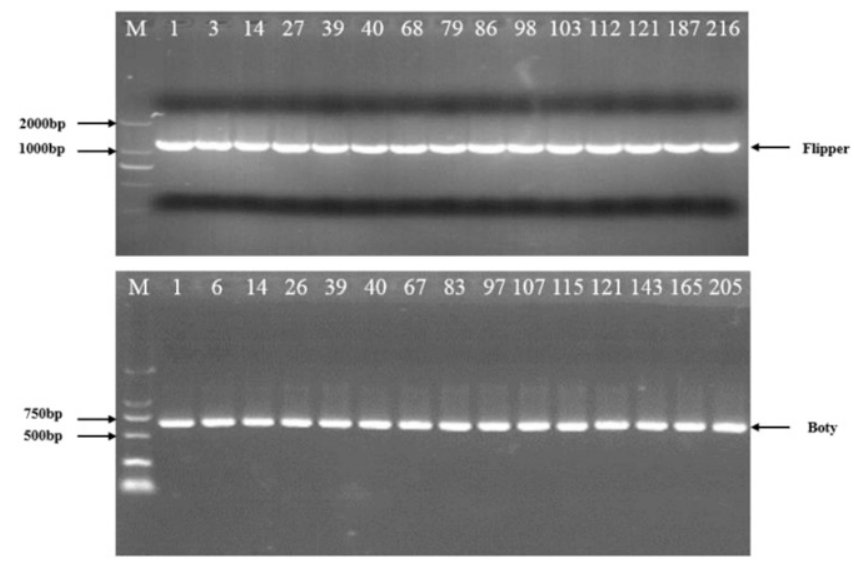

Fig. 4. Gel electrophoretic profile of Boty and Flipper amplicons amplified by Boty- and Flipper-specific primer pairs. Numerals on the top of the gel represent the isolate number. M is DNA Marker 2000, Bioteke Corporation, Beijing. 
000 Markov chain Monte Carlo (MCMC) iterations. We then used the method implemented in the program STRUCTURE HARVESTER (Earl and vonHoldt 2012) to infer the most likely value of $\mathrm{K}$. The most probable structure was determined by computing the posterior probability for each $\mathrm{K}$ using the distribution of maximum likelihoods. When the probability of ancestry of a strain in a cluster was greater than the arbitrary threshold of 0.8 , this strain was considered to be unambiguously assigned to this cluster.

\section{Results}

Morphological and phylogenetic identification of $B$. cinerea. After cultivation on PDA at $21^{\circ} \mathrm{C}$, isolates initially formed white or ashy white colonies turning gray or grayish brown. The hyphae were septate and conidiophores brown and somewhat straight, branched in upper portions with enlarged apical parts bearing clusters of conidia. Hyaline conidia were one-celled, hyaline or gray brown, ellipsoidal, ovate, or sometimes globose. Based on morphology, all 135 isolates were preliminarily identified as $B$. cinerea.
The combined G3PDH, HSP60, and RPB2 genes dataset of 36 isolates along with the sequences of other Botrytis spp. obtained from GenBank were used in the phylogenetic analysis with $M$. fructigena and $S$. sclerotiorum as outgroups. In total, 95 sequences were used in phylogenetic analyses, and 36 isolates were placed within a clade comprising five reference isolates of $B$. cinerea with $78 \%$ bootstrap support in the phylogenetic tree (Supplementary Fig. S1). This result suggested that all 36 isolates were $B$. cinerea. PCR using the primer pair C729+/- yielded an approximately 700-bp amplicon (Fig. 1), confirming that all 135 isolates were $B$. cinerea.

Mating type of $B$. cinerea. An approximately 1,050-bp band was amplified by the primer pair MATalpha5 and MATalpha3, and an approximately 1,100 -bp band was amplified by the primer pair HMG5 and HMG3 (Fig. 2). Based on the MAT loci, all 135 isolates were shown to be heterothallic. Seventy-one isolates $(52.6 \%)$ belonged to MAT1-1 type and $64(47.4 \%)$ to MAT1-2 type (Table 1). A $\chi^{2}$ test was performed to determine the goodness of fit of this distribution compared with the expected mating-type ratio of $1: 1$ :

Table 2. Frequency of the TE molecular types in B. cinerea isolates from different locations

\begin{tabular}{|c|c|c|c|c|c|c|}
\hline Viticulture climate zone & Location & transposa & Boty-only & Flipper-only & vacuma & Total \\
\hline \multirow[t]{6}{*}{ Cool-temperature area } & Lanzhou, Gansu & 6 & 6 & 2 & 1 & 15 \\
\hline & Zhangye, Gansu & 7 & 6 & 0 & 0 & 13 \\
\hline & Xingcheng, Liaoning & 5 & 2 & 1 & 0 & 8 \\
\hline & Yongning, Ningxia & 0 & 1 & 0 & 0 & 1 \\
\hline & Qingxu, Shanxi & 1 & 1 & 0 & 1 & 3 \\
\hline & Total & 19 & 16 & 3 & 2 & $\ldots$ \\
\hline \multirow[t]{7}{*}{ Medium-temperature area } & Changli, Hebei & 0 & 1 & 1 & 0 & 2 \\
\hline & Jining, Shandong & 5 & 0 & 0 & 0 & 5 \\
\hline & Longkou, Shandong & 3 & 4 & 2 & 1 & 10 \\
\hline & Laizhou, Shandong & 2 & 0 & 0 & 0 & 2 \\
\hline & Penglai, Shandong & 11 & 8 & 1 & 0 & 20 \\
\hline & Zhaoyuan, Shandong & 4 & 1 & 0 & 0 & 5 \\
\hline & Total & 25 & 14 & 4 & 1 & $\ldots$ \\
\hline \multirow[t]{6}{*}{ Warm area } & Changping, Beijing & 2 & 2 & 0 & 1 & 5 \\
\hline & Shunyi, Beijing & 1 & 0 & 0 & 0 & 1 \\
\hline & Yanqing, Beijing & 6 & 8 & 1 & 1 & 16 \\
\hline & Xingtai, Hebei & 0 & 1 & 0 & 0 & 1 \\
\hline & Chadian, Tianjin & 2 & 1 & 0 & 0 & 3 \\
\hline & Total & 11 & 12 & 1 & 2 & .. \\
\hline \multirow[t]{2}{*}{ Torrid-climate area } & Shangshui, Henan & 0 & 1 & 0 & 1 & 2 \\
\hline & Total & 0 & 1 & 0 & 1 & $\ldots$ \\
\hline \multirow{8}{*}{ Humid-tropical region } & Guilin, Guangxi & 1 & 1 & 1 & 0 & 3 \\
\hline & Zhouji, Hubei & 3 & 1 & 0 & 0 & 4 \\
\hline & Huaihua, Hunan & 4 & 0 & 0 & 0 & 4 \\
\hline & Changzhou, Jiangsu & 1 & 0 & 0 & 0 & 1 \\
\hline & Fengxian, Shanghai & 3 & 0 & 3 & 0 & 6 \\
\hline & Jiading, Shanghai & 1 & 0 & 1 & 0 & 2 \\
\hline & Hangzhou, Zhejiang & 2 & 0 & 1 & 0 & 3 \\
\hline & Total & 15 & 2 & 6 & 0 & $\ldots$ \\
\hline Total & $\ldots$ & 70 & 45 & 14 & 6 & 135 \\
\hline
\end{tabular}

Table 3. Genetic diversity indexes within the total sample and each population

\begin{tabular}{|c|c|c|c|c|c|c|}
\hline Populations & Sample size & $\mathbf{H}^{\mathbf{a}}$ & $\mathbf{I}^{\mathbf{b}}$ & MLGs $^{\mathrm{c}}$ & Genotypic diversity & $\mathbf{r}_{D}{ }^{\mathbf{d}}$ \\
\hline Boty-only & 45 & 0.28 & 0.42 & 44 & 0.9990 & 0.0300 \\
\hline Flipper-only & 14 & 0.26 & 0.39 & 13 & 0.9890 & 0.0563 \\
\hline transposa & 70 & 0.28 & 0.43 & 67 & 0.9988 & 0.0322 \\
\hline vacuma & 6 & 0.22 & 0.33 & 6 & 1.0000 & 0.0914 \\
\hline Total & 135 & 0.29 & 0.44 & 127 & 0.9991 & 0.0291 \\
\hline Cool-temperature area & 40 & 0.28 & 0.43 & 38 & 0.9974 & 0.0431 \\
\hline Warm area & 26 & 0.26 & 0.40 & 26 & 1.0000 & 0.0326 \\
\hline Humid-tropical area & 23 & 0.26 & 0.39 & 21 & 0.9921 & 0.0503 \\
\hline Medium-temperature area & 44 & 0.27 & 0.41 & 41 & 0.9968 & 0.0372 \\
\hline Total & 133 & 0.29 & 0.44 & 125 & 0.9991 & 0.0295 \\
\hline
\end{tabular}

${ }^{a}$ Nei's gene diversity.

b Shannon's information index.

${ }^{c}$ Number of multilocus genotype.

${ }^{\mathrm{d}}$ Standardized index of association. 
$\chi^{2}=0.27<\chi_{0.05,1}^{2}=3.84$ indicates that $P>0.05$ and the whole population had a 1:1 distribution of mating loci. The $\chi^{2}$ values of 0.23 , 0.02 , and 0.04 for areas with cool, medium, and warm temperatures, respectively, were significantly less than $\chi_{0.05,1}^{2}=3.84$, and the $\chi^{2}$ value of 0.70 for the humid-tropical area was also less than 3.84 . The MAT1-1 type population was dominant in areas with cool $(55.0 \%)$ and warm temperatures $(53.9 \%)$, and in humid-tropical regions $(60.9 \%)$. The MAT1-2 type population was dominant in areas with medium temperature (52.3\%) and only two isolates were found in torrid-climate areas.

Genetic group of $\boldsymbol{B}$. cinerea. The 1,171-bp band was amplified in all 135 isolates using the primer pair 262/520 L (Fig. 3) and digested at $37^{\circ} \mathrm{C}$ by $H h a \mathrm{I}$. The 517 bp band was identified in all 135 isolates, but the 601-bp band was not identified in any isolates. These results suggest that all 135 isolates belonged to Group II.

Detection of TEs. All isolates were tested for the presence of TEs using primers specific for the Boty and Flipper TEs. The Flipper primer pair amplified a 1,250-bp product, and the Boty primer pair amplified an approximately 620-bp product (Fig. 4). Seventy isolates belonged to the transposa type, 45 isolates contained only Boty, 14 isolates contained only Flipper, and 6 isolates belonged to the vacuma type (Table 2). The frequencies of the transposon distribution ranked from highest to lowest in the transposa (51.9\%), Botyonly (33.3\%), Flipper-only (10.4\%), and vacuma (4.5\%) types. The number of transposa-type isolates was highest in areas with cool temperatures, medium temperatures, and humid tropical climates, whereas warm areas contained plants with a greater number of Boty-only-type isolates. Boty-only isolates existed in all areas, and vacuma isolates were not detected in humid-tropical areas.

Genetic diversity and structure. All of the 9 SSR markers were polymorphic across the $135 \mathrm{~B}$. cinerea isolates and a total of 74 alleles were detected. The average number of alleles per locus was 8.2 , ranging from 3 to 11 . All $135 \mathrm{~B}$. cinerea isolates belonged to four TE-type populations and a total number of 127 different MLGs were identified among $135 \mathrm{~B}$. cinerea isolates. Genotypic diversity was 0.9991 . Five pairs of isolates belonged to the same TE-type and the same MLG; for example, isolates $\mathrm{H} 7$ and $\mathrm{H} 40$ belonged to transposa and were the same MLG. Three pairs of isolates belonged to different TE-type but the same MLG; for example, H1 belonged to transposa type and H6 belonged to Boty-only type, but they were the same MLG. The other 119 isolates belonged to different 119 MLGs. Separate examination of the four TE-type populations confirmed the overall low level of gene diversity, with the Nei's gene diversites ranging from 0.22 to 0.28 , and the Shannon's information index between 0.33 and 0.43 (Table 3). The transposa population isolates showed higher genetic diversity than other populations when considering the Nei's gene diversity and Shannon's information index. Isolates from the vacuma population showed the lowest genetic diversity.

Pairwise tests of genetic differentiation among four TE-type populations yielded generally low to high Gst values. The highest value

Table 4. Pairwise estimates of Gst (above diagonal) and $\mathrm{Nm}$ (below diagonal) among four TE-type populations

\begin{tabular}{lcccc}
\hline & Boty-only & Flipper-only & transposa & vacuma \\
\hline Boty-only & $\ldots$ & 0.0931 & 0.0139 & 0.0357 \\
Flipper-only & 4.8730 & $\ldots$ & 0.0713 & 0.1664 \\
transposa & 35.5168 & 6.5081 & $\ldots$ & 0.0593 \\
vacuma & 13.5096 & 2.5048 & 7.9374 & $\ldots$ \\
\hline
\end{tabular}

Table 5. Pairwise estimates of Nei's unbiased genetic identity (above diagonal) and genetic distance (below diagonal) among four TE-type populations

\begin{tabular}{lcccc}
\hline & Boty-only & Flipper-only & transposa & vacuma \\
\hline Boty-only & $\ldots$ & 0.9331 & 0.9927 & 0.9912 \\
Flipper-only & 0.0693 & $\ldots$ & 0.9504 & 0.8913 \\
transposa & 0.0074 & 0.0508 & $\ldots$ & 0.9725 \\
vacuma & 0.0089 & 0.1151 & 0.0279 & $\ldots$ \\
\hline
\end{tabular}

$(G s t=0.1664)$ was obtained between Flipper-only population and vacuma population, showing high genetic differentiation between these two populations. The lowest value $(G s t=0.0139)$ and the highest $\mathrm{Nm}$ value $(\mathrm{Nm}=35.5168)$ were observed between Boty-only population and transposa population, suggesting that very strong gene flow existed between these two populations and they had very low genetic differentiation (Table 4). Pairwise tests of Nei's genetic identity and genetic distance also supported the genetic differentiation (Table 5). A more detailed analysis based on AMOVA partition of the total genetic variance indicated that most of the variation $(95.77 \%)$ occurred within the populations. Genetic variation among populations was only $4.23 \%$ (Table 6).

The $\Delta \mathrm{k}$ statistic gave the highest value at $\mathrm{k}=2(\Delta \mathrm{k}=533.54)$, and all the 135 isolates belonged to two genetic clusters (Fig. 5). The cluster 1 contained 44 isolates with an average $Q$ value of $0.86(68.2 \%$ of them with $\mathrm{Q}>0.80$ ), and the cluster 2 contained 91 isolates with an average $Q$ value of 0.92 (84.6\% of them with $Q>0.80)$. The average Q-values of cluster 2 were more than 0.66 in transposa, Boty-only, and vacuma populations, and the average Q-value of cluster 2 was up to 0.86 in vacuma populations. The average Q-value of cluster 1 was 0.72 in Flipper-only populations (Fig. 6).

Population genetic diversity and structure analyses were performed in four viticulture climatic zone populations, with the exception of the torrid-climate area population, in which only two isolates were collected. In four viticulture climatic zone populations, genetic diversity was similar. The $\mathrm{Nm}$ values were higher than 18 and strong gene flow existed among cool, warm, and medium-temperature areas. These three populations showed very low genetic differentiation and the genetic distances were lower than 0.015 (Table 7 and Table 8). The average Q-values of cluster 2 were more than 0.68 in cool-temperature-area, warm-area, and medium-temperature-area populations (Fig. 7). The $\mathrm{Nm}$ values were lower than 7 between humid-tropical area population and other three populations, and the genetic differentiations were moderate with genetic distances higher than 0.05. The average Q-value of cluster 1 was 0.66 in humidtropical area population. A more detailed analysis based on AMOVA partition of the total genetic variance indicated that most of the variation $(94.73 \%)$ occurred within the populations. Genetic variation among populations was only $5.27 \%$ (Table 9 ).

The estimate of linkage disequilibrium was equally low in total population, and Linkage disequilibrium $\left(\mathrm{r}_{\mathrm{D}}\right)$ was low $\left(\mathrm{r}_{\mathrm{D}}<0.1\right)$ in four TE-type populations and four viticulture climatic zone populations, suggesting the occurrence of limited genetic recombination in all groups (Table 3).

\section{Discussion}

The genotypic diversity of $B$. cinerea isolates has been intensively studied in various locations around the world (Esterio et al. 2011; Isenegger et al. 2008; Johnston et al. 2014; Kecskeméti et al. 2014; Kumari et al. 2014; Moyano et al. 2003; Muñoz et al. 2002). However, in China, B. cinerea isolates collected from Solanaceae vegetables (Zhejiang Province) (Yin 2006), rapes (Hubei Province) (Zhang 2010a), broad beans (Hebei, Jiangsu, and Sichuan provinces, etc.) (Huang 2012), tomatoes (Hebei and Shanxi provinces, Beijing, etc.) (Qiao et al. 2014), and strawberries (Hebei, Anhui, and Liaoning provinces, etc.) (Zhang 2015) were tested for the presence of transposons or their mating type or PCR-RFLP for the $B c-h c h$ locus. This is the first study on the genotypic diversity of $B$. cinerea isolates from grape vineyards in China.

The teleomorph of $B$. cinerea is not often observed under natural conditions, and research on the mating type of $B$. cinerea from grapes

Table 6. Hierarchical analysis of molecular variance (AMOVA) with four TE-type populations

\begin{tabular}{lrrcc}
\hline $\begin{array}{l}\text { Source of } \\
\text { variation }\end{array}$ & d.f. & $\begin{array}{c}\text { Sum of } \\
\text { squares }\end{array}$ & $\begin{array}{c}\text { Variance } \\
\text { components }\end{array}$ & $\begin{array}{c}\text { Percentage of } \\
\text { variation }\end{array}$ \\
\hline Among populations & 3 & 69.325 & 0.462 & 4.23 \\
Within populations & 131 & 1372.216 & 10.475 & 95.77 \\
Total & 134 & 1441.541 & 10.937 & $\ldots$ \\
\hline
\end{tabular}


has been minimal. Delcán and Melgarejo (2002) detected 31\% homothallic $B$. cinerea isolates and $69 \%$ heterothallic $B$. cinerea isolates from bean, tomato, cucumber, etc. in Spain. Beever and Weeds (2004) considered that sexual reproduction between the two mating types of $B$. cinerea, MAT1-1 and MAT1-2, is a minor cause of the observed genetic diversity because the sexual structures of the fungus are rarely observed in the field. Detection of the mating-type distribution is the simplest way to ascertain the potential for sexual recombination and evolution. When a 1:1 ratio is observed between mating types within a population, the population is assumed to be randomly mating because of the apparent frequency-dependent selection of each type (Wessels 2012). In our study, 52.6\% of the isolates belonged to the heterothallic MAT1-1 type, $47.4 \%$ belonged to the heterothallic MAT1-2 type. A $\chi^{2}$ test indicated that the ratio of MAT1-1 and MAT1-2 in the whole population significantly fit the expected mating-type ratio of $1: 1$, which agrees with the results of Kumari et al. (2014) and Zhang (2015). The mating-type $\chi^{2}$ values ranged from 0.02 to 0.70 in all viticulture climatic zones (Table 1), which were less than $\chi_{0.05,1}^{2}=3.84, P>0.05$, and indicate that the mating-type distribution fit the expected ratio of $1: 1$ in every viticulture climatic zone. The two isolates obtained from the area with a torrid climate were both MAT1-2 type; additional isolates need to be collected and analyzed from this area. Qiao et al. (2014) detected the mating type of $183 \mathrm{~B}$. cinerea isolates from tomatoes in several planting regions, and all isolates were heterothallic (either MAT1-1 or

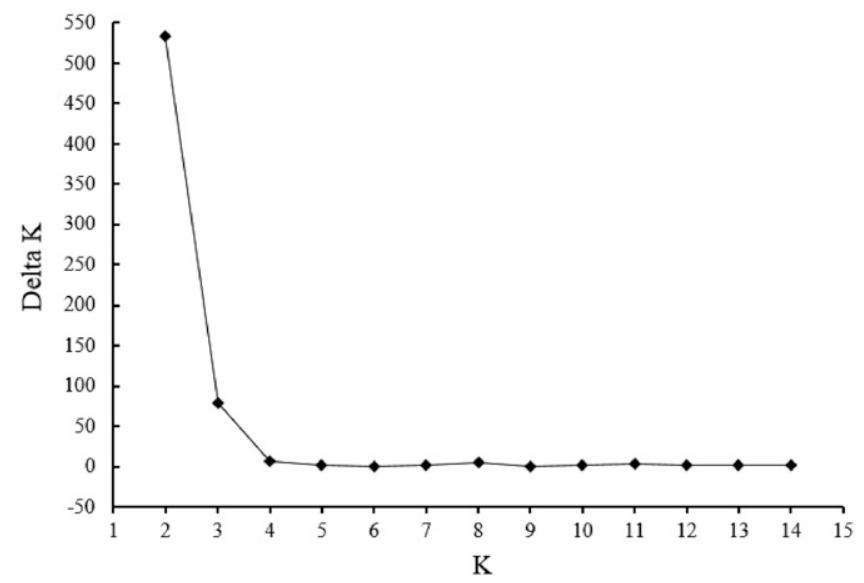

Fig. 5. Estimates of the rate of change of the slope of the log probability curve $(\Delta \mathrm{k})$ calculated plotted against $\mathrm{k}$.
MAT1-2), while the mating type distribution did not fit the expected mating-type ratio of 1:1, which was different from this study.

The population of $B$. cinerea was divided into Groups I and II based on PCR-RFLP of the Bc-hch locus. This approach has been widely applied, and most isolates appear to belong to Group II. Kecskeméti et al. (2014) collected 33 B. cinerea isolates from Rheingau, a German grapevine-growing region, and found that all belonged to Group II. The 55 isolates collected from the Bio-Bio region in Chile also belonged to Group II. Isenegger et al. (2008) and Esterio et al. (2011) detected B. cinerea isolates from South Asia, Australia, and the Central Valley of Chile and they also belonged to Group II. The number of Group I isolates was small in all studies globally (Zhang et al. 2017). Walker et al. (2011) named Group I B. pseudocinerea, and Group II was still called B. cinerea. Saito et al. (2014) first reported gray mold caused by $B$. pseudocinerea on blueberries in North America. Zhou et al. (2014) and Saito et al. (2016) detected several isolates belonging to Group I that were different from $B$. pseudocinerea in their morphology and phylogeny and named them B. sinoviticola and B. californica, respectively. Botrytis sinoviticola was detected in Kunming, Wuhan, and Shihezi in China. This study lacked isolates from these locations because they were not in our initial assigned research area. Li et al. (2015) reportedly isolated and identified B. pseudocinerea from tomatoes in Qianjiang County, Hubei Province, China. In this study, most isolates were collected from Beijing, Gansu, Liaoning, and Shandong, which are in northern China. We also amplified the $B c-h c h$ locus and digested it with $H h a \mathrm{I}$, with the result that all isolates belonged to Group II despite a few differences in the morphology of some isolates. No isolates belonged to Group I.

TEs, characterized by their ability to "jump" or transpose within a genome, make up a large fraction of the eukaryotic genome and have a substantial impact on genome function and evolution. Based on the presence or absence of Boty and Flipper, B. cinerea isolates were divided into four molecular genotypes including transposa, Boty-only, Flipper-only, and vacuma. The corresponding numbers in this study in each genotype were $70(51.9 \%), 45(33.3 \%), 14(10.4 \%)$, and 6 $(4.5 \%)$ (Table 2), which was similar to the results in Hungary (Váczy et al. 2008) and New Zealand (Johnston et al. 2014). Although the frequency of the transposa type was highest in the total population and most subpopulations (each viticulture climatic zone), the Botyonly type was highest in warm areas (46.2\%). Vacuma isolates were mainly distributed in northern China (including cool, medium, warm, and torrid-temperature areas), although in only small amounts. Flipper-only isolates were mainly distributed in humid-tropical areas (42.9\%). Yin (2006) found that $25.2 \%$ of $B$. cinerea isolates from Solanaceae vegetables in Zhejiang, China, were of the Flipper-only type, which was greater than the frequency of Boty-only isolates but

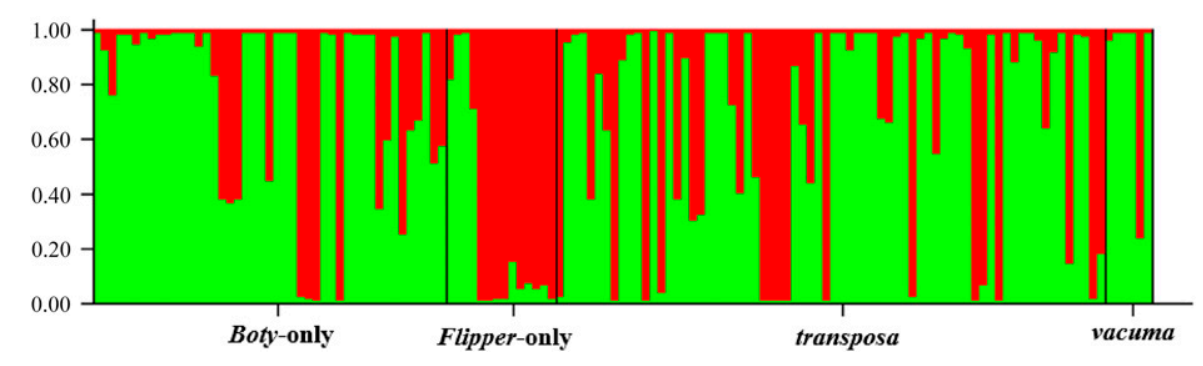

Fig. 6. Bayesian assignment on $B$. cinerea isolates from four TE-type populations to each of the $\mathrm{K}=2$ identified clusters (red $=$ genetic cluster 1 , green $=$ genetic cluster 2). Each bar represents the estimated membership coefficient $(Q)$ for each isolate in each cluster. TE-types of populations were indicated at the bottom of the graph.

Table 7. Pairwise estimates of Gst (above diagonal) and Nm (below diagonal) among four viticulture climatic zone populations

\begin{tabular}{lcccc}
\hline & Cool-temperature area & Warm area & Humid-tropical area & Medium-temperature area \\
\hline Cool-temperature area & $\ldots$ & 0.0185 & 0.0740 & 0.0197 \\
Warm area & 26.5746 & $\ldots$ & 0.0855 & 0.0257 \\
Humid-tropical area & 6.2555 & 5.3470 & $\ldots$ & 0.0710 \\
Medium-temperature area & 24.8464 & 18.9377 & 6.5470 & $\ldots$ \\
\hline
\end{tabular}


equal to the frequency of vacuma isolates. Abdel Wahab (2015) detected $B$. cinerea isolates from different hosts, including grapes, lettuce, and strawberries, in Egypt and obtained a transposon frequency distribution of transposa type, Boty-only type, Flipper-only type, and vacuma type, ranked from highest to lowest. This pattern is the same as that observed in China and in New Zealand vineyards (Johnston et al. 2014) located in the warm and humid Auckland region, with high numbers of Flipper-only isolates at flowering. Muñoz and Campos (2013) analyzed $B$. cinerea from pine and eucalyptus nurseries in the Bio-Bio region (Chile) and obtained 55 isolates; the frequencies of the transposa and Boty-only types were $43.6 \%$ and $47.3 \%$, respectively, and no Flipper-only isolates were detected. Kumari et al. (2014) found that the number of Flipper-only isolates was highest in India and Southeast Nepal, which belong to tropical climatic zones. The number of Boty-only isolates was highest in central Nepal, a warm climatic zone. In California (Ma and Michailides 2005), 195 of 234 isolates were of the transposa type, and no Flipper-only isolates were detected. We found that the Flipper-only type was mainly distributed in the warm and tropical humid climatic zones of the world.

The genetic distances between microsatellite haplotypes were not concordant with the transposon type groupings but were associated with geographic origin in a previous study (Isenegger et al. 2008). However, in this study, the genetic distances between Boty-only population and transposa and vacuma were all very low, and moderate differentiation $(G s t=0.0593)$ and the higher gene flow $(\mathrm{Nm}=$ 7.9374) were found between transposa and vacuma populations, which may be a consequence that Boty-only isolates could result from a cross between vacuma and transposa isolates (Fournier and Giraud 2008; Fournier et al. 2002; Muñoz et al. 2002). The gene flow between Flipper-only and transposa populations was higher $(\mathrm{Nm}=$ 6.5081), while the gene flow between Flipper-only and vacuma populations was lower $(\mathrm{Nm}=2.5048)$. This result could indicated that Flipper-only isolates did not easily lose Flipper to become vacuma isolates. Therefore, the genetic differentiation between Flipper-only and vacuma populations was very high $(\mathrm{Gst}=0.1664)$. Previously, it was proposed that transposa and vacuma were genetically isolated and they were found in sympatry on various hosts irrespective of geography (Giraud et al. 1997, 1999). Similarly, the genetic identity between transposa and vacuma populations was 0.9725 in this study, and the genetic distance was only 0.0279 between these two populations. We divided $B$. cinerea isolates into four populations based on viticulture climatic zone origin in this study (Table 7). The cool-temperature area and warm area were in geographic proximity, and the gene flow between cool-temperature area population and warm area population was highest $(\mathrm{Nm}=26.5746)$, and the genetic differentiation between these two populations was lowest $(\mathrm{Gst}=0.0185)$. The humid-tropical area was farther from other three zones, and the gene flow between the humid-tropical area population and the other three populations was lower $(\mathrm{Nm}<6.55)$, and the genetic differentiation between the humid-tropical area population and the other three populations was higher (Gst > 0.07) (Table 7). The result could indicate that the gene flow and genetic differentiation had a certain correlation with geographic origin.

Structure analyses did not indicate that $B$. cinerea isolates belonged to different TE types and were clustered according to the presence or absence of the transposable element. All isolates belonged to two clusters, vacuma populations belonged to cluster 2, and the average Q-values of cluster 2 were more than 0.66 in transposa and Boty-only populations. The average Q-value of cluster 21 was 0.72 in the Flipper-only population. The Flipper-only population was very different from other populations. Analysis of MP-PCR markers had shown that there was no clear relationship between transposon types and FenR phenotypes isolates (Ma and Michailides 2005). Isenegger et al. (2008) analyzed B. cinerea isolates from South Asia and Australia; four genetic clusters were detected, but structure analysis supported the geographic grouping from three distinct locations and showed that the same transposon types from different geographic origin did not cluster together. In addition, genetic assignment tests and Bayesian analyses did not indicate that $B$. cinerea isolates containing a mycovirus and/or a transposable element were clustered according to the presence of the respective genetic element; instead, obtained clusters in STRUCTURE analyses were composed of isolates with and without genetic elements, irrespective of their geographic origin or crop management practice (Kecskeméti et al. 2014). In this study, warm area populations belong to cluster 2 , and the average Q-values of cluster 2 were 0.70 and 0.69 in the cool-temperature area population and the medium-temperature area

Table 8. Pairwise estimates of Nei's unbiased genetic identity (above diagonal) and Nei's genetic distance (below diagonal) among four viticulture climatic zone populations

\begin{tabular}{lcccc}
\hline & Cool-temperature area & Warm area & Humid-tropical area & Medium-temperature area \\
\hline Cool-temperature area & $\ldots$ & 0.9919 & 0.9468 & 0.9892 \\
Warm area & 0.0081 & $\ldots$ & 0.9411 & 0.9864 \\
Humid-tropical area & 0.0547 & 0.0607 & $\ldots$ & 0.9508 \\
Medium-temperature area & 0.0109 & 0.0137 & 0.0505 & $\ldots$ \\
\hline
\end{tabular}

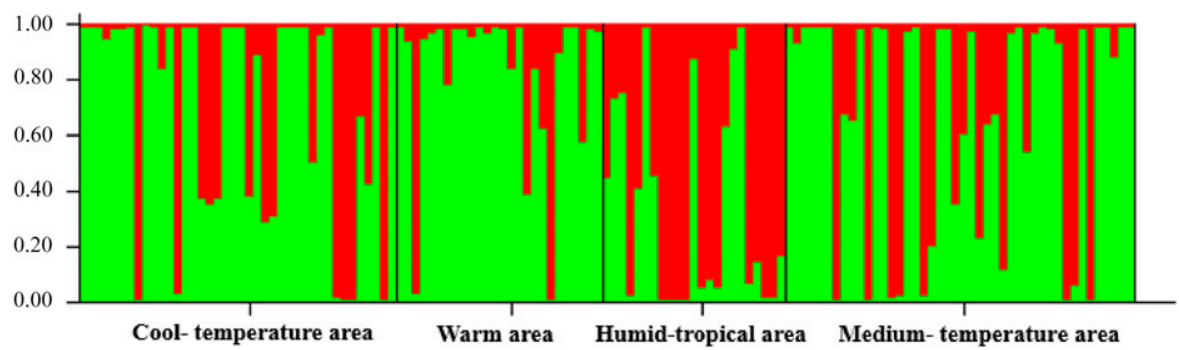

Fig. 7. Bayesian assignment on $B$. cinerea isolates from four viticulture climatic zone populations to each of the $K=2$ identified clusters (red $=$ genetic cluster 1 , green $=$ genetic cluster 2). Each bar represents the estimated membership coefficient $(Q)$ for each isolate in each cluster. The viticulture climatic zones of populations were indicated at the bottom of the graph.

Table 9. Hierarchical analysis of molecular variance (AMOVA) with four viticulture climatic zone populations

\begin{tabular}{lrccc}
\hline Source of variation & d.f. & Sum of squares & Variance components & Percentage of variation \\
\hline Among populations & 3 & 86.949 & 0.575 & 5.27 \\
Within populations & 129 & 1332.449 & 10.329 & 94.73 \\
Total & 132 & 1419.398 & 10.904 & $\ldots$ \\
\hline
\end{tabular}


population, respectively. The average Q-value of cluster 1 was 0.66 in humid-tropical area population. Huang et al. (2014) found that $92 \mathrm{~B}$. cinerea MLGs belonged to two genetic clusters, Chongqing and Sichuan populations belonged to one cluster, the Qinghai population belonged to another cluster, and Jiangsu, Hebei, and Gansu population contained those two clusters. The population genetic structure had a certain correlation with the TE type and geographic origin.

The result of this work indicated that there is rich genetic variation among B. cinerea isolates from grapes in China. Four TE-types and two genetic clusters were observed. The analysis of genetic diversity and genetic structure would be useful in understanding and controlling B. cinerea in grapes in China.

\section{Acknowledgments}

This research was supported by the National Natural Science Foundation of China (Grant No. 31572050), and the Special Fund Project of Modern Agricultural Industry Technology System of China (Grant No. CARS-29).

\section{Literature Cited}

Abdel Wahab, H. A. 2015. Characterization of Egyptian Botrytis cinerea isolates from different host plants. Adv. Microbiol. 5:177-189.

Agapow, P. M., and Burt, A. 2001. Indices of multilocus linkage disequilibrium. Mol. Ecol. Notes 1:101-102.

Beever, R. E., and Weeds, P. L. 2004. Taxonomy and genetic variation of Botrytis and Botryotinia. Pages 29-52 in: Botrytis: Biology, Pathology and Control. Y. Elad, B. Williamson, P. Tudzynski, and N. Delen, eds. Kluwer Academic Press, Dordrecht, The Netherlands.

Dean, R., van Kan, J. A. L., Pretorius, Z. A., Hammond-Kosack, K. E., Pietro, A. D., Spanu, P. D., Rudd, J. J., Dickman, M., Kahmann, R., Ellis, J., and Foster, G. D. 2012. The top 10 fungal pathogens in molecular plant pathology. Mol. Plant Pathol. 13:414-430.

Debuchy, R., and Turgeon, B. G. 2006. Mating-type sturcture evolution and function in Euascomycetes. Pages 293-323 in: Growth, Differentiation and Sexuality. Kües, U., and Fischer, R., eds. Springer-Verlag, Berlin, Heidelberg.

Delcán, J., and Melgarejo, P. 2002. Mating behavior and vegetative compatibility in Spanish populations of Botryotinia fuckeliana. Eur. J. Plant Pathol. 108: 391-400.

Diolez, A., Marches, F., Fortini, D., and Brygoo, Y. 1995. Boty, a long-terminalrepeat retroelement in the phytopathogenic fungus Botrytis cinerea. Appl. Environ. Microbiol. 61:103-108.

Earl, D. A., and Vonholdt, B. M. 2012. STRUCTURE HARVESTER: a website and program for visualizing structure output and implementing the Evanno method. Conserv. Genet. Resour. 4:359-361.

Esterio, M., Muñoz, G., Ramos, C., Cofré, G., Estévez, R., Salinas, A., and Auger, J. 2011. Characterization of Botrytis cinerea isolates present in Thompson seedless table grapes in the Central Valley of Chile. Plant Dis. 95:683-690.

Excoffier, L., Laval, S., and Schneider, G. 2005. Arlequin version 3.0: an integrated software package for population genetics data analysis. Evol. Bioinform. Online 1:47-50.

Faretra, F., Antonacci, E., and Pollastro, S. 1988. Sexual behaviour and mating system of Botryotinia fuckeliana, teleomorph of Botrytis cinerea. J. Gen. Microbiol. 134:2543-2550.

Ferrada, E. E., Latorre, B. A., Zoffoli, J. P., and Castillo, A. 2016. Identification and characterization of Botrytis blossom blight of Japanese plums caused by Botrytis cinerea and B. prunorum sp. nov. in Chile. Phytopathology 106: 155-165.

Fournier, E., and Giraud, T. 2008. Sympatric genetic differentiation of a generalist pathogenic fungus, Botrytis cinerea, on two different host plants, grapevine and bramble. J. Evol. Biol. 21:122-132.

Fournier, E., Giraud, T., Albertini, C., and Brygoo, Y. 2005. Partition of the Botrytis cinerea complex in France using multiple gene genealogies. Mycologia 97:1251-1267.

Fournier, E., Giraud, T., Loiseau, A., Vautrin, D., Estoup, A., Solignac, M., Cornuet, J. M., and Brygoo, Y. 2002. Characterization of nine polymorphic microsatellite loci in the fungus Botrytis cinerea (Ascomycota). Mol. Ecol. Notes 2:253-255.

Fournier, E., Levis, C., Fortini, D., Leroux, P., Giraud, T., and Brygoo, Y. 2003. Characterization of Bc-hch, the Botrytis cinerea homolog of the Neurospora crassa het-c vegetative incompatibility locus, and its use as a population marker. Mycologia 95:251-261.

Gai, J. Y. 2000. Methods of Experimental Statistics. China Agriculture Press, China.

Giraud, T., Fortini, D., Levis, C., Lamarque, C., Leroux, P., LoBuglio, K., and Brygoo, Y. 1999. Two sibling species of the Botrytis cinerea complex, transposa and vacuma, are found in sympatry on numerous host plants. Phytopathology 89:967-973.

Giraud, T., Fortini, D., Levis, C., Leroux, P., and Brygoo, Y. 1997. RFLP markers show genetic recombination in Botryotinia fuckeliana (Botrytis cinerea) and transposable elements reveal two sympatric species. Mol. Biol. Evol. 14:1177-1185.
He, P. C. 1999. Grapevine Science. China Agriculture Press, Beijing, China.

Huang, Y. 2012. Identification of pathogens causing chocolate spot on broad bean (Vicia fabae) and resistance resource screening. Master's thesis, Hebei Normal University of Science \& Technology, China.

Huang, Y., Zhu, Z. D., Duan, C. X., Wu, X. F., and Dongfang, Y. 2014. Genetic diversity of Botrytis cinerea isolates from broad bean. Sci. Agric. Sin. 47: 2335-2347

Isenegger, D. A., Ades, P. K., Ford, R., and Taylor, P. W. J. 2008. Status of the Botrytis cinerea species complex and microsatellite analysis of transposon types in South Asia and Australia. Fungal Divers. 29:17-26.

Johnston, P. R., Hoksbergen, K., Park, D., and Beever, R. E. 2014. Genetic diversity of Botrytis in New Zealand vineyards and the significance of its seasonal and regional variation. Plant Pathol. 63:888-898.

Kecskeméti, E., Brathuhn, A., Kogel, K. H., Berkelmann-Löhnertz, B., and Reineke, A. 2014. Presence of transposons and mycoviruses in Botrytis cinerea isolates collected from a German grapevine growing region. J. Phytopathol. 162:582-595.

Kumari, S., Tayal, P., Sharma, E., and Kapoor, R. 2014. Analyses of genetic and pathogenic variability among Botrytis cinerea isolates. Microbiol. Res. 169: 862-872.

Levis, C., Fortini, D., and Brygoo, Y. 1997. Flipper, a mobile Fot1-like transposable element in Botrytis cinerea. Mol. Gen. Genet. 254:674-680.

Li, N., Zhang, J., Yang, L., Wu, M. D., and Li, G. Q. 2015. First report of Botrytis pseudocinerea causing gray mold on tomato (Lycopersicon esculentum) in central China. Plant Dis. 99:283.

Lu, J. Y. 2001. Plant Pathogenic Mycology. China Agriculture Press, China.

Ma, Z., and Michailides, T. J. 2005. Genetic structure of Botrytis cinerea populations from different host plants in California. Plant Dis. 89:1083-1089.

Mirzaei, S., Goltapeh, E. M., Shams-Bakhsh, M., and Safaie, N. 2008 Identification of Botrytis spp. on plants grown in Iran. J. Phytopathol. 156: 21-28.

Moyano, C., Alfonso, C., Gallego, J., Raposo, R., and Melgarejo, P. 2003 Comparison of RAPD and AFLP marker analysis as a means to study the genetic structure of Botrytis cinerea populations. Eur. J. Plant Pathol. 109: 515-522.

Muñoz, C., Talquenca, S. G., Oriolani, E., and Combina, M. 2010. Genetic characterization of grapevine-infecting Botrytis cinerea isolates from Argentina. Rev. Iberoam. Micol. 27:66-70.

Muñoz, G., and Campos, F. 2013. Genetic characterization of Botrytis cinerea isolates collected from pine and eucalyptus nurseries in Bio-Bio Region, Chile. For. Pathol. 43:509-512.

Muñoz, G., Hinrichsen, P., Brygoo, Y., and Giraud, T. 2002. Genetic characterisation of Botrytis cinerea populations in Chile. Mycol. Res. 106: 594-601.

Pritchard, J. K., Stephens, M., and Donelly, P. 2000. Inference of population structure using multilocus genotype data. Genetics 155:945-959.

Qiao, G. H., Li, X. H., Lin, X. M., Huang, J. B., and Zhou, Y. 2014. Analysis and molecular detection of Botrytis cinerea mating type genes. Mycosystema 33 $1-10$

Rigotti, S., Gindro, K., Richter, H., and Viret, O. 2002. Characterization of molecular markers for specific and sensitive detection of Botrytis cinerea, Pers.: Fr. in strawberry (Fragaria $\times$ ananassa Duch.) using PCR. FEMS Microbiol. Lett. 209:169-174.

Saito, S., Margosan, D., Michailides, T. J., and Xiao, C. L. 2016. Botrytis californica, a new cryptic species in the $B$. cinerea species complex causing gray mold in blueberries and table grapes. Mycologia 108:330-343.

Saito, S., Michailides, T. J., and Xiao, C. L. 2014. First report of Botrytis pseudocinerea causing gray mold on blueberry in North America. Plant Dis. 98:1743.

Staats, M., van Baarlen, P., and van Kan, J. A. L. 2005. Molecular phylogeny of the plant pathogenic genus Botrytis and the evolution of host specificity. Mol. Biol Evol. 22:333-346.

Tamura, K., Stecher, G., Peterson, D., Filipski, A., and Kumar, S. 2013. MEGA 6 molecular evolutionary genetics analysis 6.0. Mol. Biol. Evol. 30:2725-2729.

Thompson, J. R., and Latorre, B. A. 1999. Characterization of Botrytis cinerea from table grapes in Chile using RAPD-PCR. Plant Dis. 83:1090-1094.

Váczy, K. Z., Sándor, E., Karaffa, L., Fekete, E., Fekete, É., Árnyasi, M., Czeglédi, L., Kövics, G. J., Druzhinina, I. S., and Kubicek, C. P. 2008. Sexual recombination in the Botrytis cinerea populations in Hungarian vineyards. Phytopathology 98:1312-1319.

van Kan, J. A. L., Duarte, J., Dekkers, E., Dyer, P. S., and Kohn, L. M. 2010. The Botrytis cinerea mating type loci. Cádiz, Spain: XV International Botrytis symposium.

Walker, A., Gautier, A., Confais, J., Martinho, D., Viaud, M., Pêcheur, P. L., Dupont, J., and Fournier, E. 2011. Botrytis pseudocinerea, a new cryptic species causing gray mold in French vineyards in sympatry with Botrytis cinerea. Phytopathology 101:1433-1445.

Wessels, B. A. 2012. Genetic characterization and fungicide resistance profiles of Botrytis cinerea in rooibos nurseries and pear orchards in the Western Cape of South Africa. Master's thesis, Stellenbosch University, South Africa.

Yeh, F., Yang, R. C., Boyle, T. B. J., Ye, Z. H., and Mao, J. X. 1999. POPGENE, The User-friendly Shareware for Population Genetic Analysis. Molecular Biology and Biotechnology Center, University of Alberta, Canada. 
Yin, L. M. 2006. The resistance of Botrytis cinerea to fungicide pyrimethanil in Solanaceae vegetables. Master's thesis, Zhejiang University, China.

Zhang, J. 2010a. Studies on taxonomy of Botrytis species in Hubei province and diversity of $B$. cinerea. Ph.D. thesis, Huazhong Agricultural University, China.

Zhang, J. 2010b. The screening and characterization of Botrytis cinerea mutants generated by T-DNA insertion. Master's thesis, Agricultural University of Hebei, China.

Zhang, J. 2015. Diversity of pathogens of gray mold from the main strawberry production regions in China. Ph.D. thesis, China Agricultural University, China.

Zhang, W., Qiao, G. H., Huang, J. B., Wang, Z. Y., and Li, X. H. 2013. Evaluation on resistance of grape gray mold pathogen Botrytis cinerea to pyrimethanil in China. Sci. Agric. Sin. 46:1208-1212.
Zhang, Y. J., Shen, F. Y., Xu, H. P., Li, Y. N., and Liu, D. Q. 2017. Research advances in the diversity of Botrytis cinerea. J. Agric. Biotechnol. 25:954-968.

Zhang, J., Wu, M. D., Li, G. Q., Yang, L., Yu, L., Jiang, D. H., Huang, H. C., and Zhuang, W. Y. 2010a. Botrytis fabiopsis, a new species causing chocolate spot of broad bean in central China. Mycologia 102:1114-1126.

Zhang, J., Zhang, L., Li, G. Q., Yang, L., Jiang, D. H., Zhuang, W. Y., and Huang, H. C. 2010b. Botrytis sinoallii, a new species of the gray mold pathogen on Allium crops in China. Mycoscience 51:421-431.

Zhou, Y. J., Zhang, J., Wang, X. D., Yang, L., Jiang, D. H., Li, G. Q., Hsiang, T. and Zhuang, W. Y. 2014. Morphological and phylogenetic identification of Botrytis sinoviticola, a novel cryptic species causing gray mold disease of table grapes (Vitis vinifera) in China. Mycologia 106:43-56. 